\title{
تيارات الفكر العربي الإسلامي المعاصر وتحولات العصر وتداعياته" أنور الزعبي
}

\section{محمد سلاّم جميعان}

يُعدّ هذا الكتاب؛ الذي نقف على مر اجعته؛ و افياً في موضوعه، شاملاًً في منحســاه

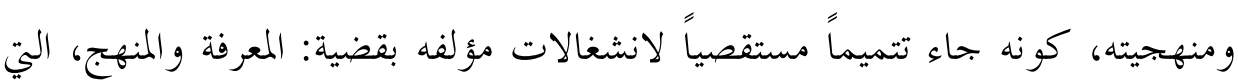

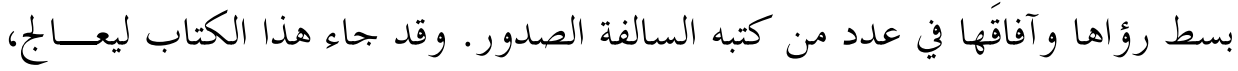

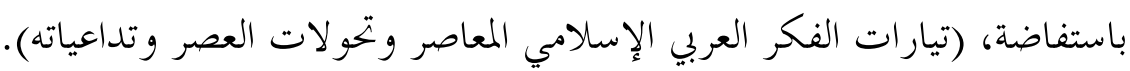

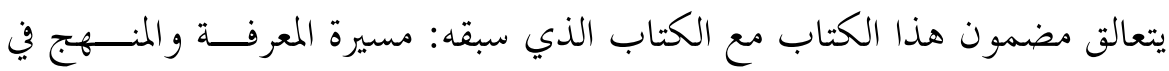

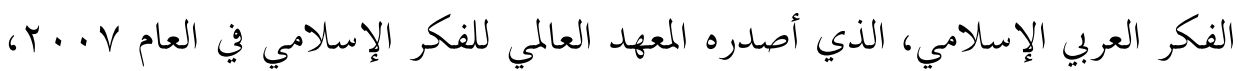

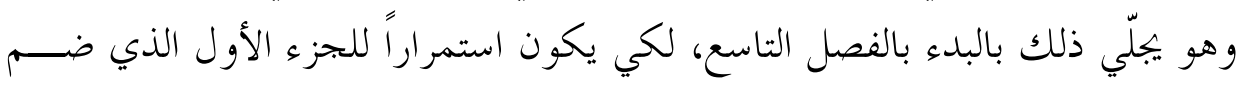

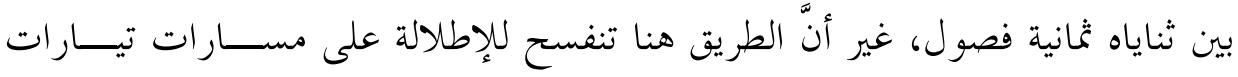

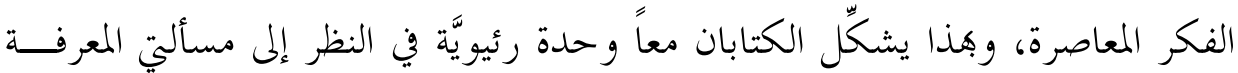

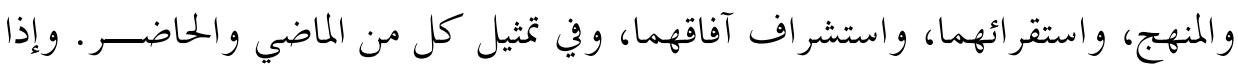

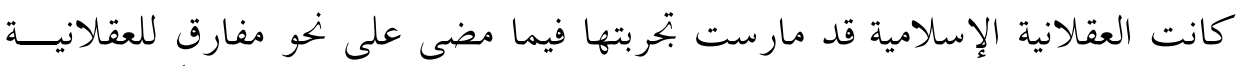

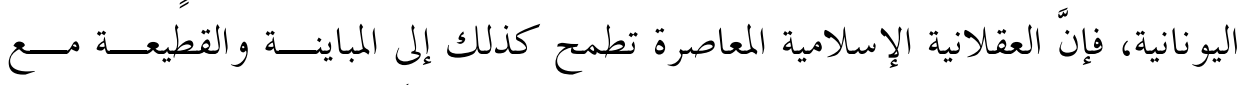

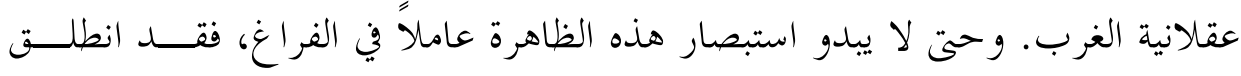

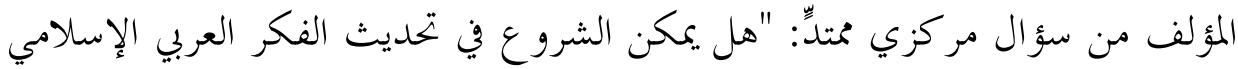

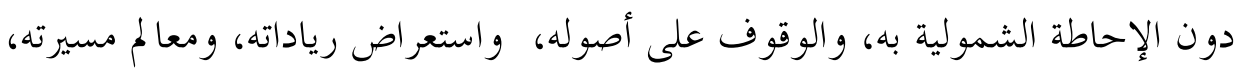

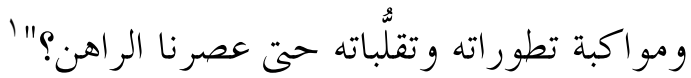

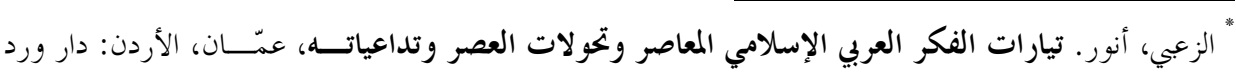

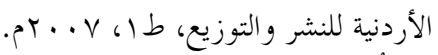
باحثُ ومفكر إسلاميّ يممل دكتوراه الدولة في الفلسفة، وألّف ثلاثة عشر كتاباً في أبرز قضايا الفكر العــربي

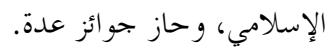

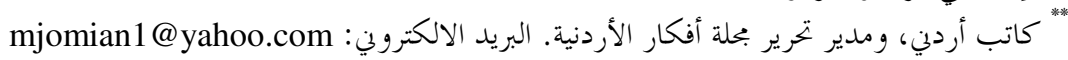

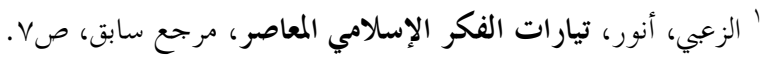




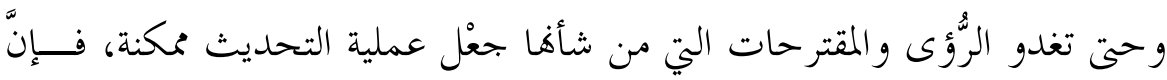
المؤلف يقدم منهجية نقدية يرى أها ملائمة للتحديث، تقوم على سبر مفاهيم أساسية

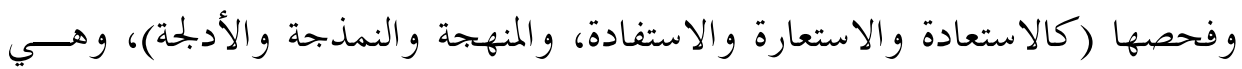

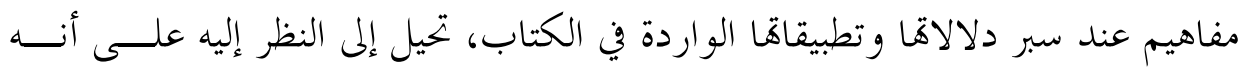

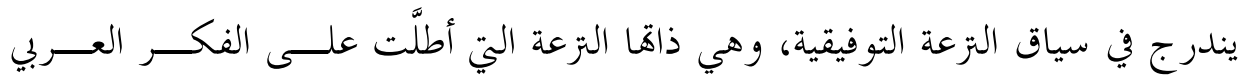

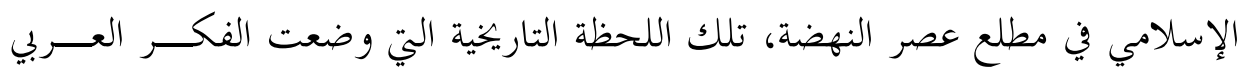

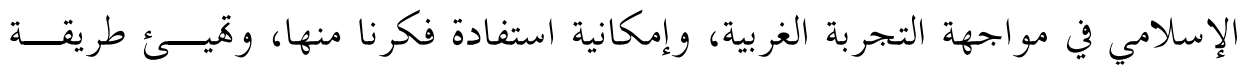

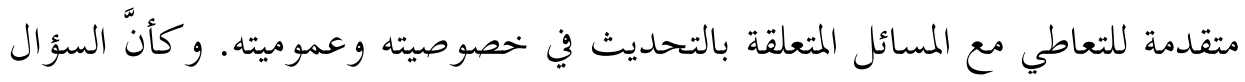

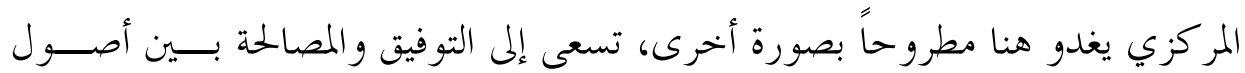

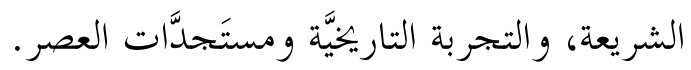

في الفصل التاسع، الذي يُعدُّ الفصل الأول في هذا الكتاب، يسرد المؤلف ســيرة

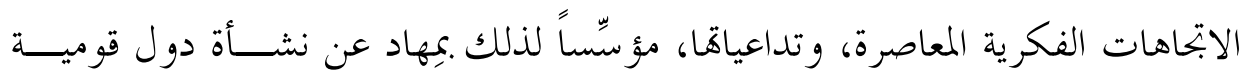

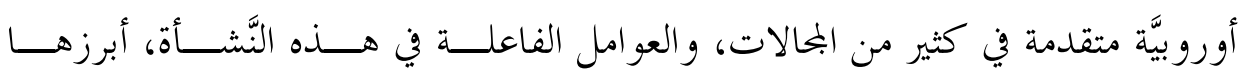

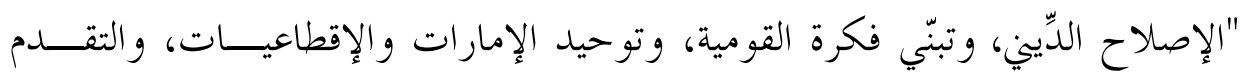

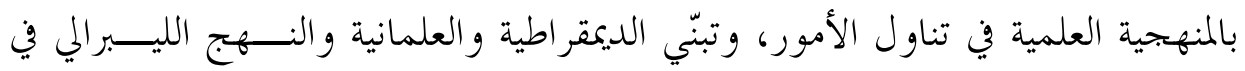

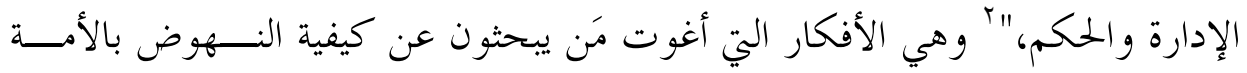

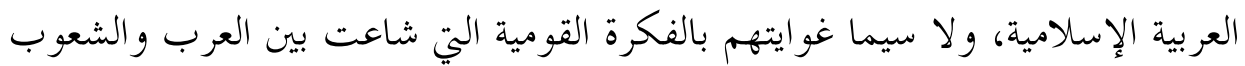
الهندية و البلقانية، وحتى التركية. وقد تمثّلت هذه التعة الإحيائية في حركات وبتمّمات وأحزاب وثورات مختلفة،

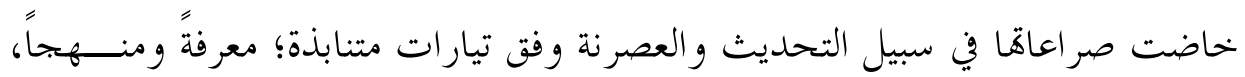

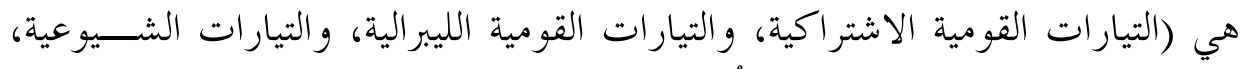

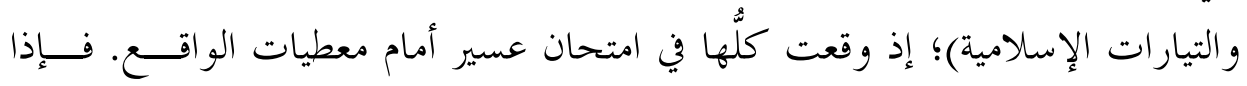

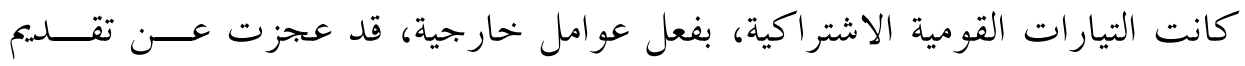




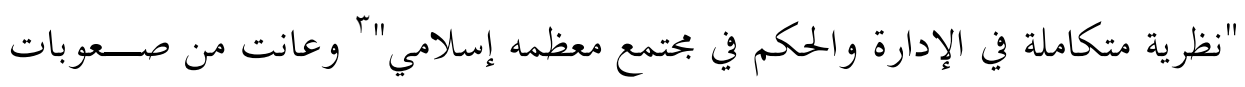

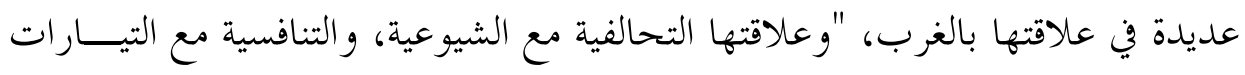

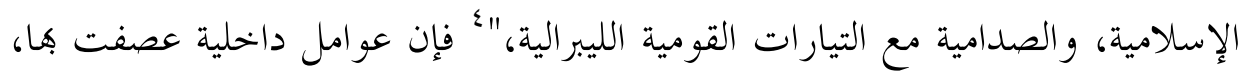

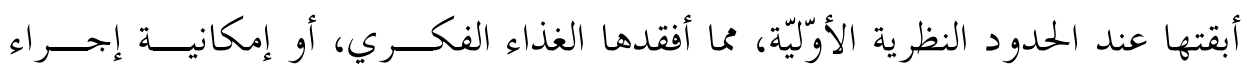

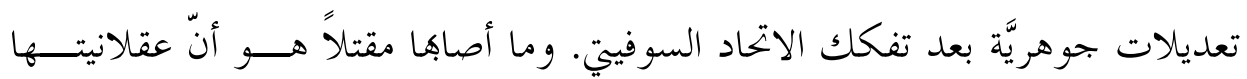

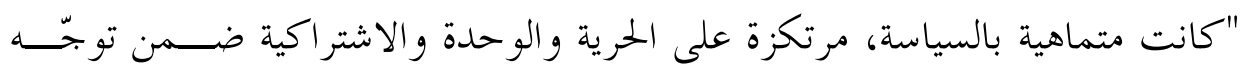

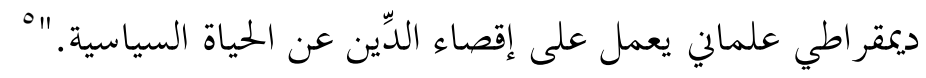
أمّا التيارات القومية الليبرالية، فقد استمدَّت بقاءها واستمرارها بدعم من الغرب، "الذي رتَّب لهم استلام السلطة، و كانت هذه نقطة ضعف لا يمكن تحاوزها،" "فقيامها على الذَّائعية ومصانعة الغرب في منهجه الليبرالي، جعل عقلانيتها مستعارة ومتــأثرة

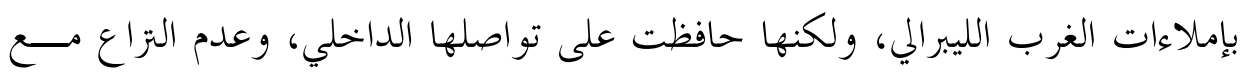

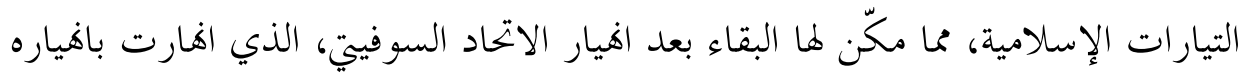

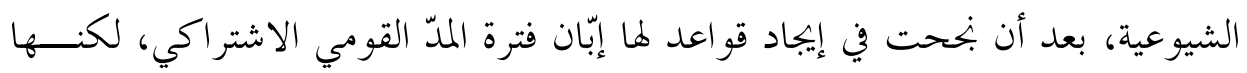

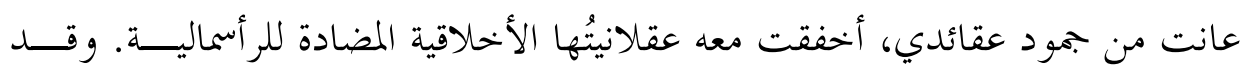
ملأت التيارات الإسلامية الفراغ الذي تركته التيارات السالف ذكرها بقوّة. ويعود المؤلف هنا إلى التركيز على سيرة (الاستعادة والاستئناف) التي انساق إليها

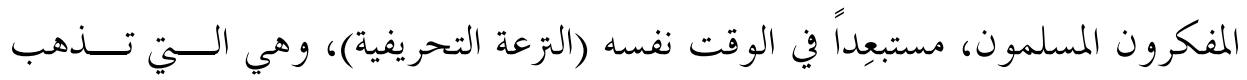

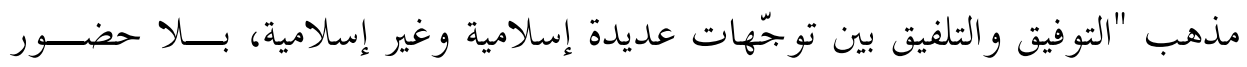

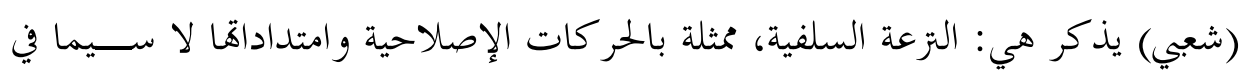

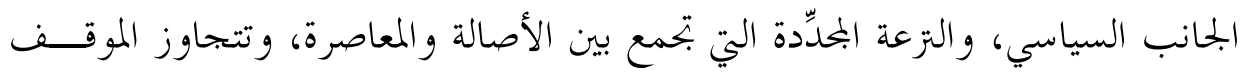

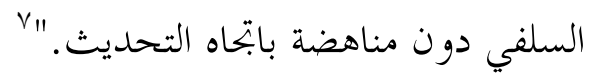

$$
\begin{aligned}
& \text { " المرجع السابق، ص ص ا . } \\
& \text { ؛ المرجع السابق، صرجع الساب، صبا. } \\
& \text { • المرجع السابق، صبع السابق، صبا. }
\end{aligned}
$$

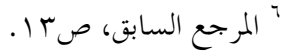

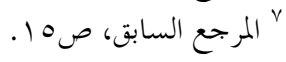




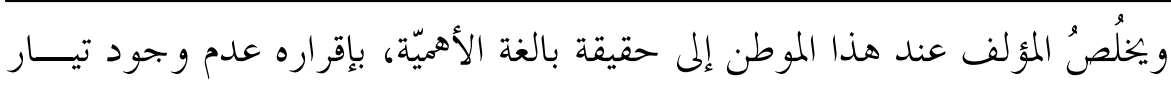
قوميٍِ يتبنى معتقَد الإسلام إضافة إلى فكرة القومية، أو تيار إسلامي يتبنى فكرة القومية

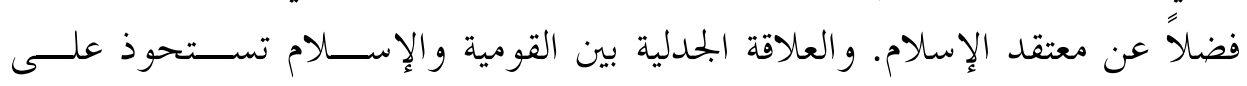
صفحات عدّة؛ إذ يرى المؤلف ضرورةها في الخلاص من الواقع العربي الآسن نحو آفاق

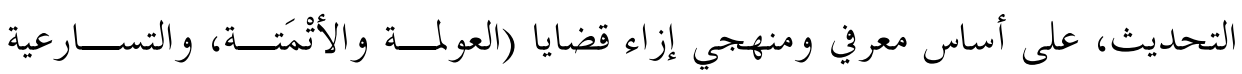

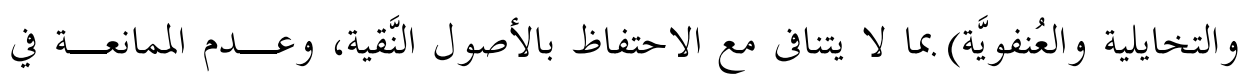

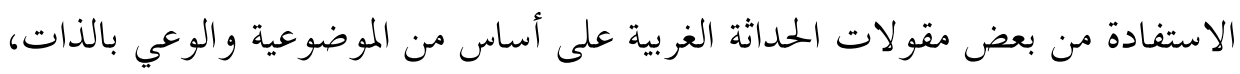

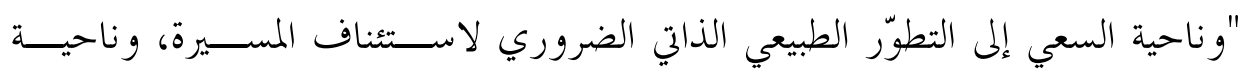

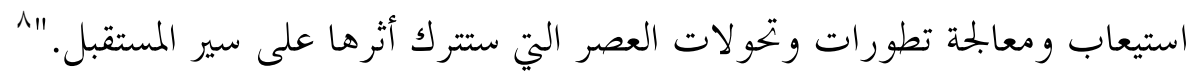

ووي سبيل تأصيل مستوى الوعي بالآخر والذات، يقف المؤلف في الفصل العاشر

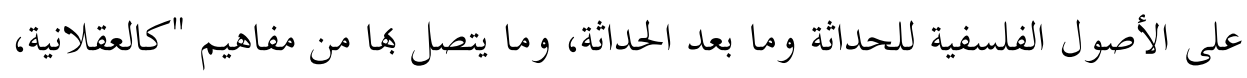

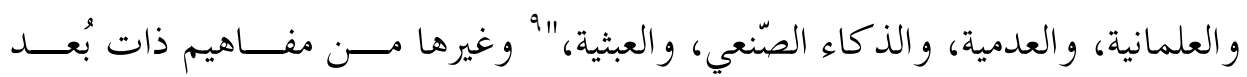

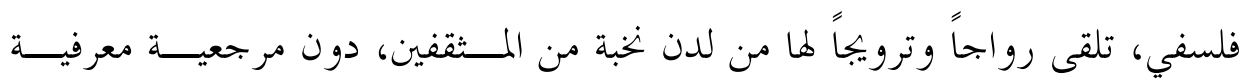

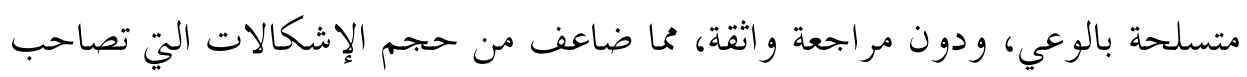

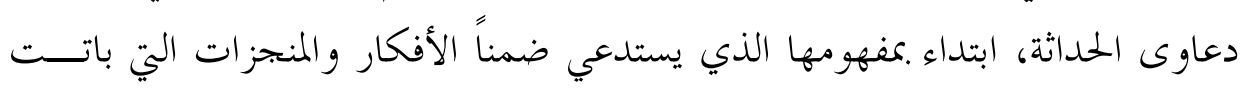

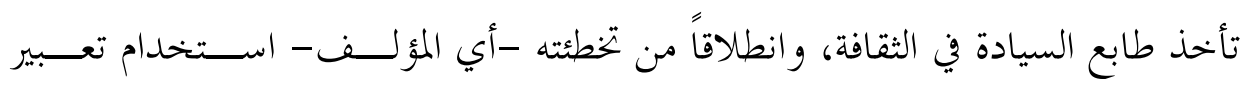

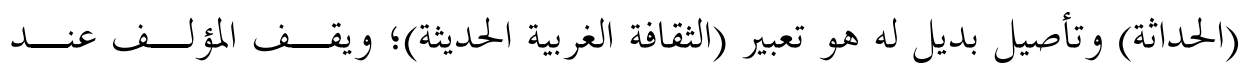

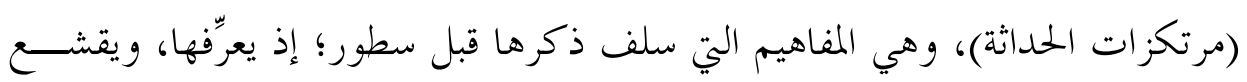

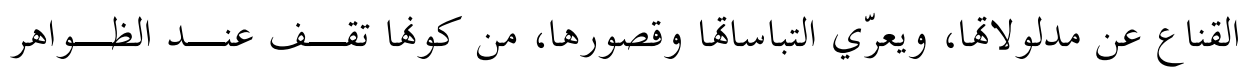

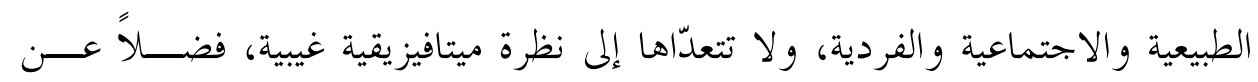

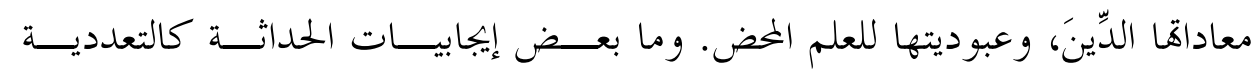

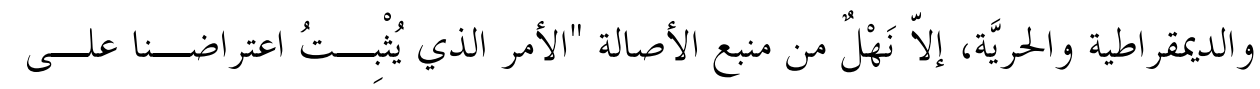




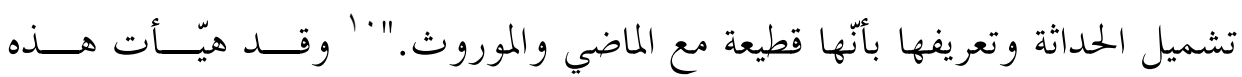

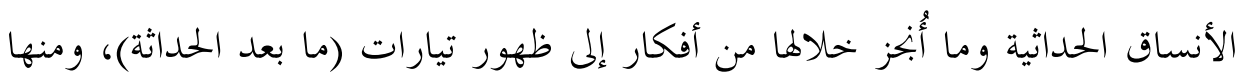

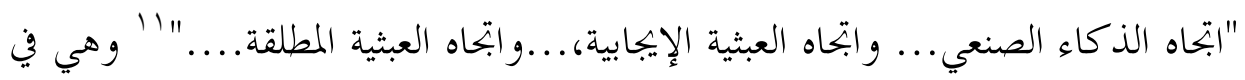

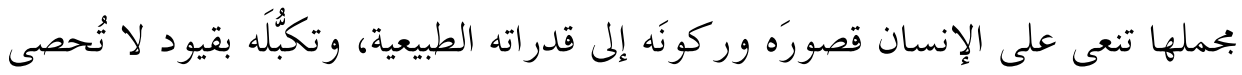

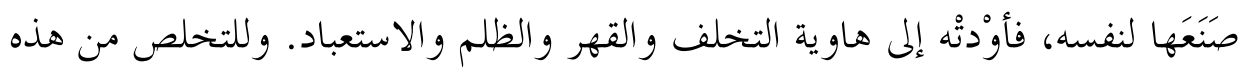

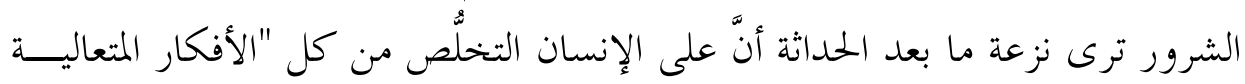

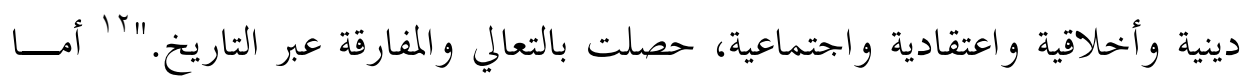
الاتحاه الرابع فلا يرى في الحماثة كل المساوئ، ولكنه يصفها بأها قاصرة وغير مكتملة

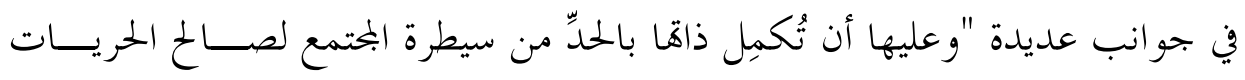

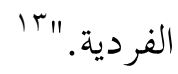

و بنــزعة نابعة من رفض مفاهيم الحداثة وما بعد الحماثة، ينهز المؤلف إلى تحليلها

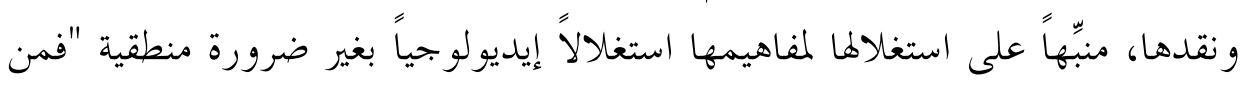

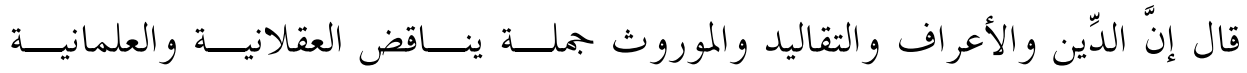

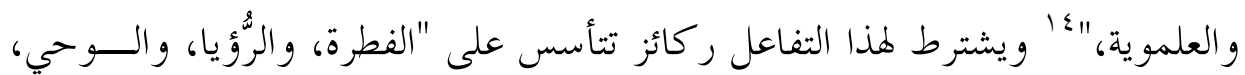

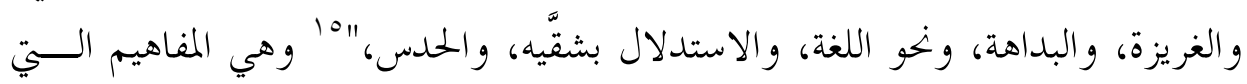
تتعاضد في تشكيل رؤيته للكشف عن طبيعة تموضع (المعرفة و العبادة في الشريعة)، التي

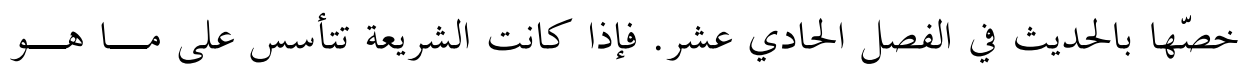
عقلي منهجي، فإن العبادة تتأسس على ما هو معرفي، وهو ما دفع بالتجربة الإسلامية للتّرّي و التسامي، نظرياً وعملياً، وأوصلها إلى مرتبة القدوة التي احتذها كثير من الأمم فئم

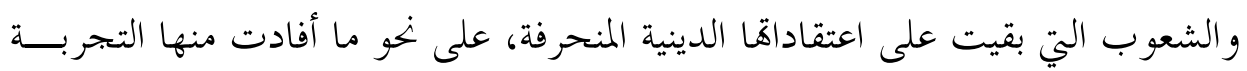

$$
\begin{aligned}
& \text { •' المرجع السابق، صهب. }
\end{aligned}
$$

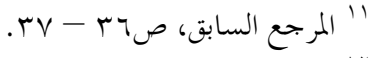

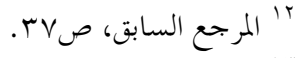

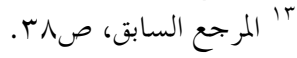

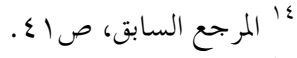

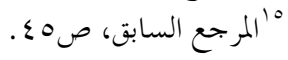




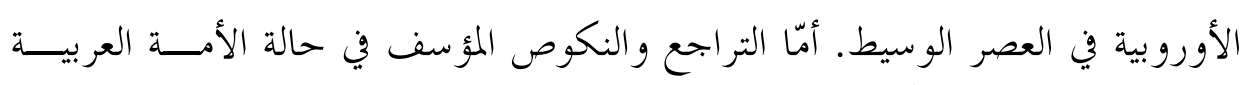

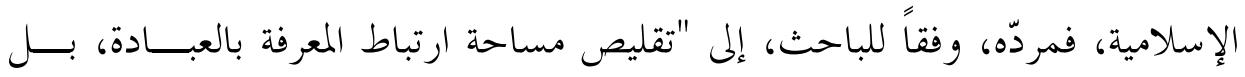

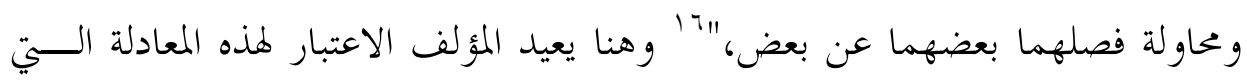

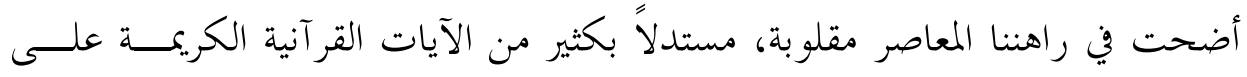

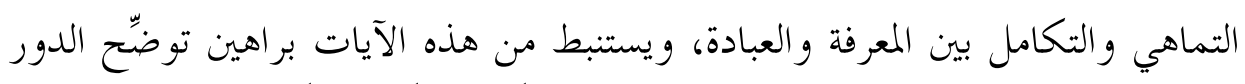

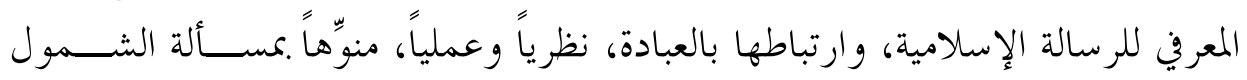

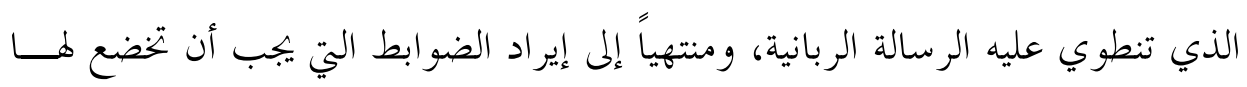

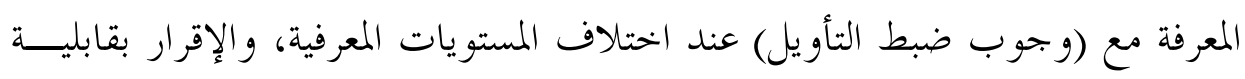

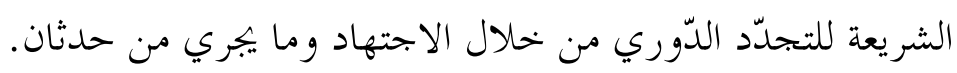

وهذا الوقوف على سير الفكر العربي الإسلامي، والإطلالــة التفصــيلية المتأنيــة

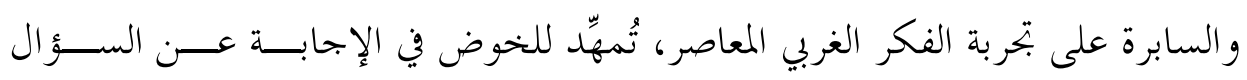

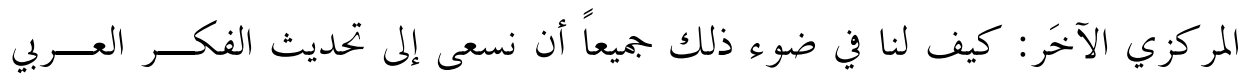

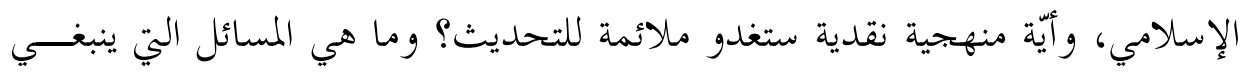

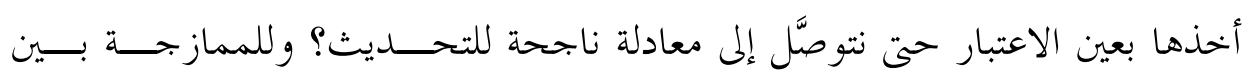

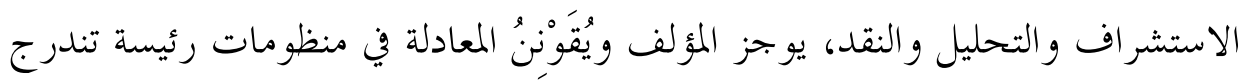

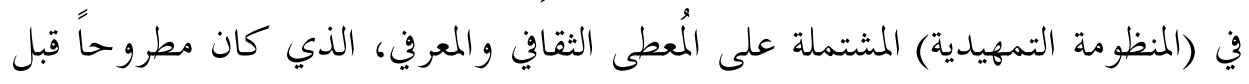

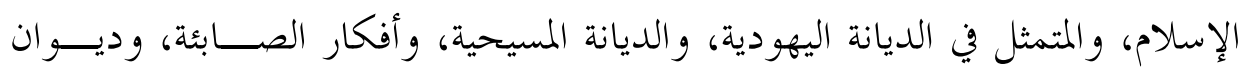

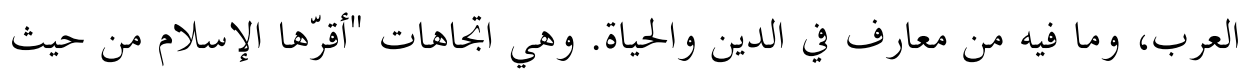

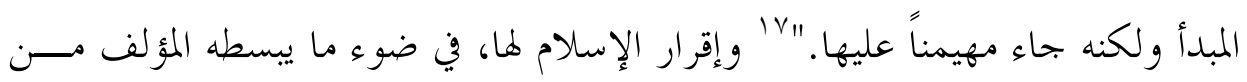

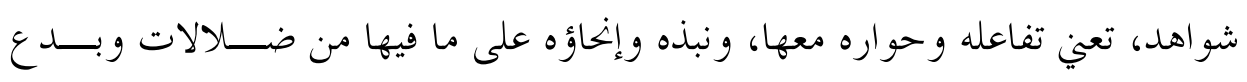

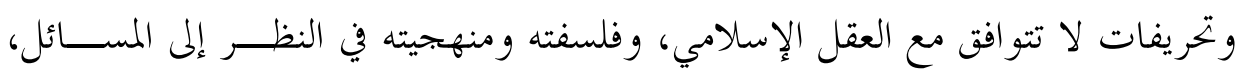

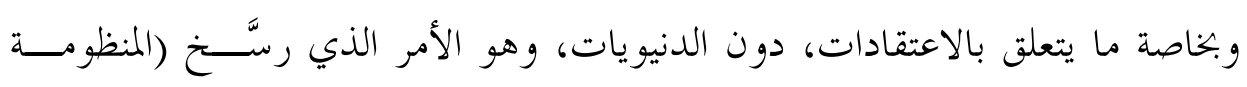




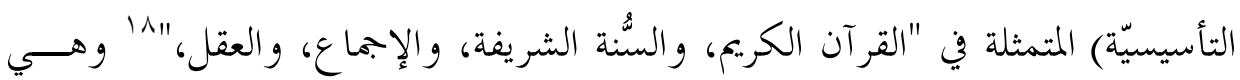

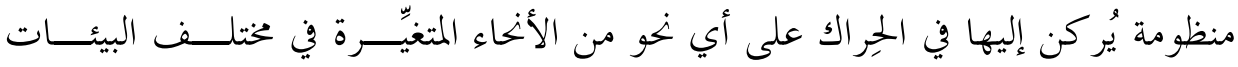

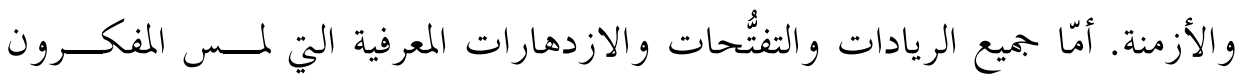

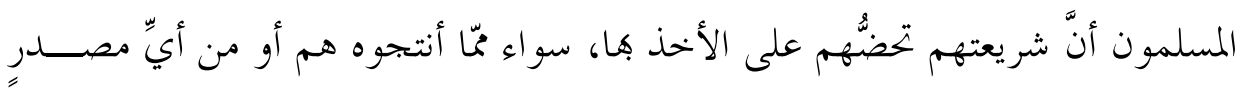

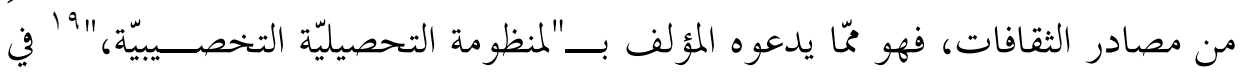
حين يندرج التفكير المنطقي والمنهجي بكل أشكاله وصـــوره البحديــة، ذات الأبعــاد

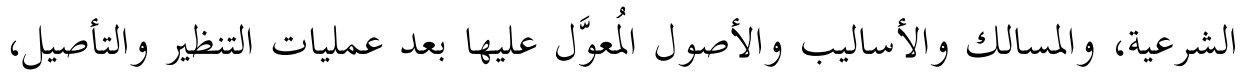

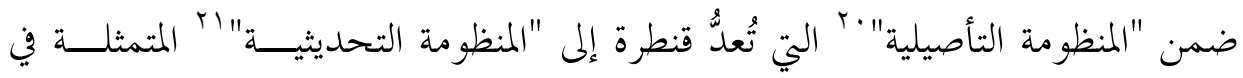

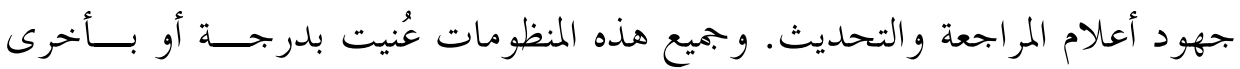
ببحث "علاقة العقل بالنقل، و الظاهر و الباطن، وطبيعة العقلانية التي ينبغي اعتمادهـــا،

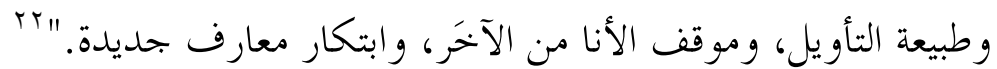

ولقد كان لكل منظومة من هذه المنظومات دوره الفاعل، على تباين في التصـــالح

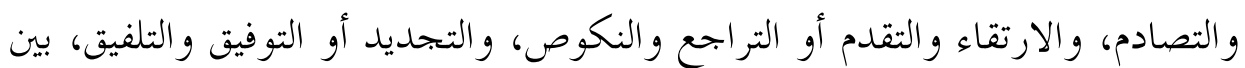

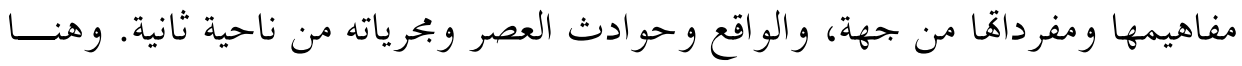

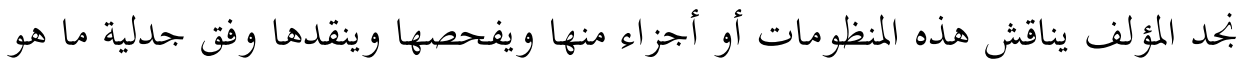
عربي صرف، وما هو إسلامي مضض، منوِّاً بأثر المصادر غير العربية وغير الإسلامية في وني تشكيل مفهوم الفكر العربي الإسلامي.

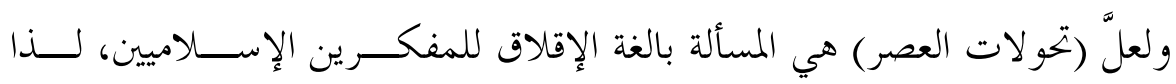

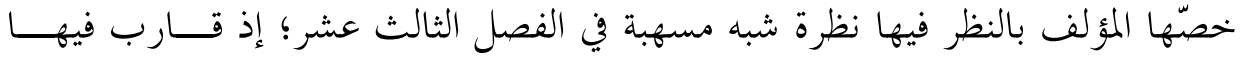

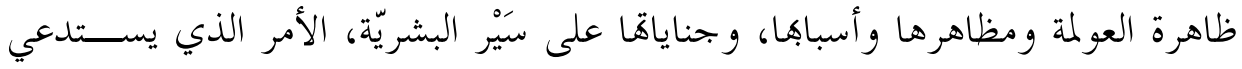

$$
\begin{aligned}
& \text { ^' المرجع السابق، ص77. }
\end{aligned}
$$

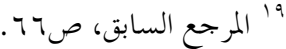

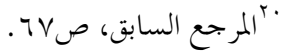

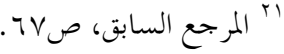

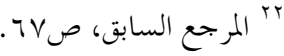


أنسنة العولمة. كما قارب المؤلف هنا ظو اهر "العلمنة و الأتمتة و التســــارعية و الذرائعيـــة

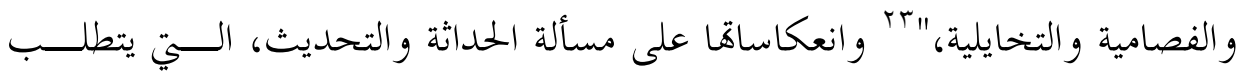

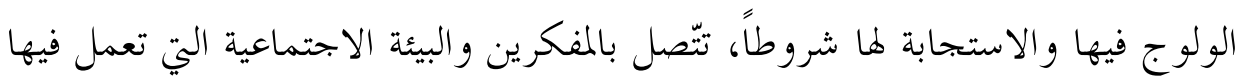

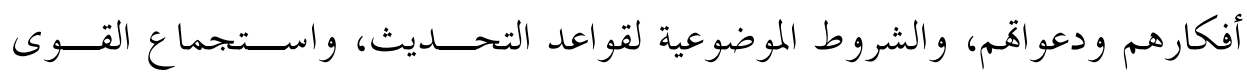

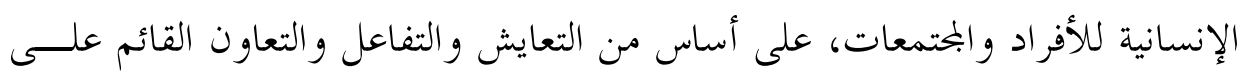
أسس وتشريعات تنظٍّم هذه المهام و المطلو بات.

ويطرح المؤلف في الفصل الرابع عشر (المعالجة الناجعـــة للتحــــيث) في ضـــوء الحاضر، وقضايا العصر وتحوّلاته. وهو هنا ينطلق من رؤية متصلة بالتاريخ الحضاري،

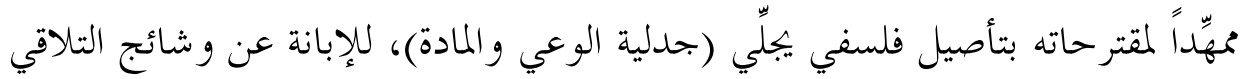

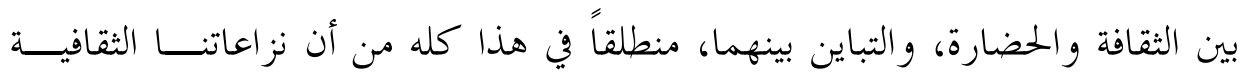
و الفكرية الحضارية تعود في الأصل إلى تباين فهمنا واستيعابنا الأدوات التي تضطلع هـا

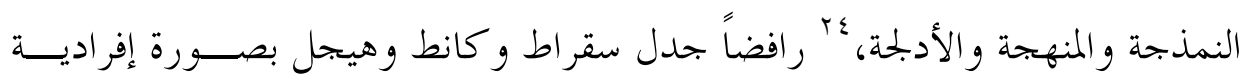

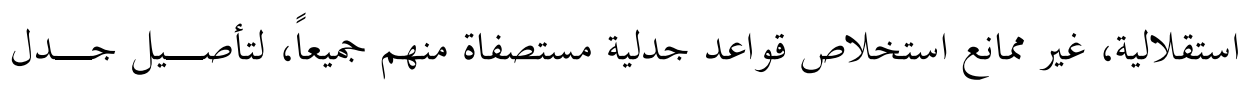
معياري نموذجي (يناسب الصيرورة التي تحكم بحتمعنا). فالفكر .ماديّته ورو حانيته يمكن

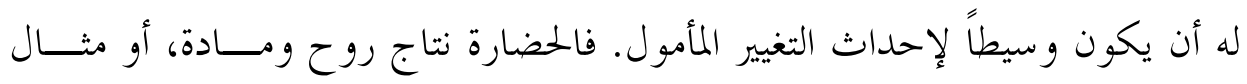

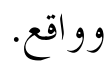

وبين الآن و الآخَر يعيد المؤلف طرح سؤ اله المركزي”، ليمتدَّ بالحديث عن تصارع

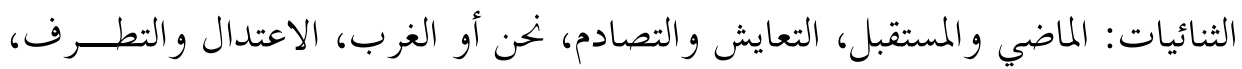
وغيرها من الثنائيات، التي ما زالت تبسط ظِلالها على الراهن الإسلامي المرير. و ونلحظ هنا جنوح المؤلف إلى التأشير على الحالة السياسية بفعل وجود عوامل غير بريئة يراها

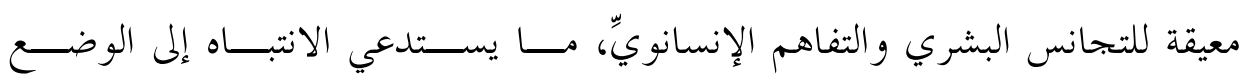
الجيوسياسي القائم على نشدان التحديث الانقلابي أو التدريجي على السواء. 
ولأن الفكر لا يعمل في الفراغ، فقد ختم المؤلف كتابه بالفصل الخامس عشــر، و فيه يستكمل خطوات المنهجية التي استرشدها، ابتغاء الركون إلى نموذج يمكن تحقيقه. وهذا استدعى منه الإطلال على تشابك الفكر العربي الإسلامي بالتطورات السياسـية

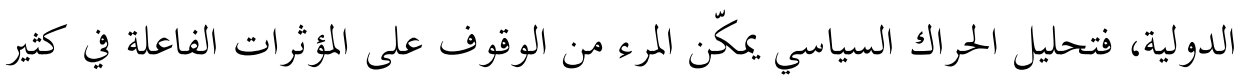
من القضايا الإسلامية، التي انفعلت بنظرة الغرب إليها على صعيدي الغزو السياسـي

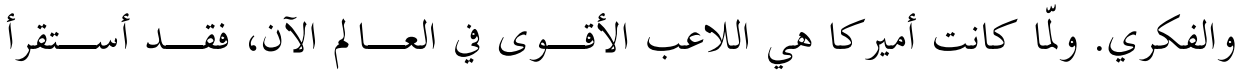
استشر افها لما يمكن أن تؤول إليه أحوال العالم في ظل القوة الصينية والعقيدة الإسلامية،

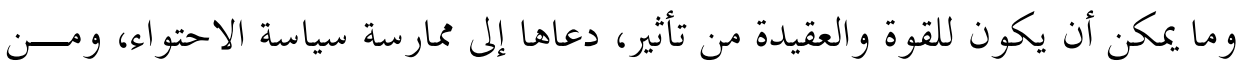

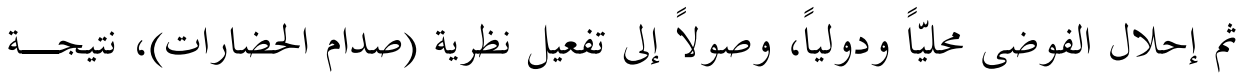
تعميم الحداثة الليبرالية لفرض لاهوها وعقيدها السياسية على العالم.

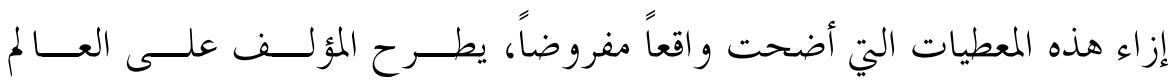

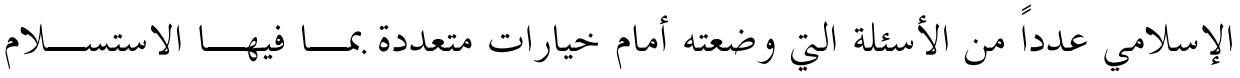

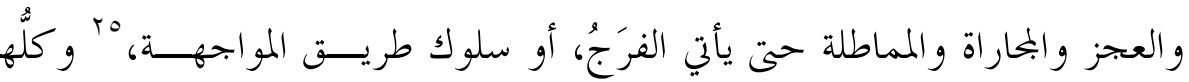

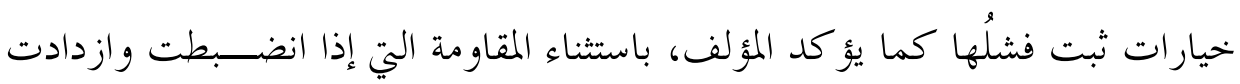
و اتسع نطاقها، تحقق للأمة تأطير التوازن بين المبادئ والمصالح. وهنا يغدو تقديم نموذج

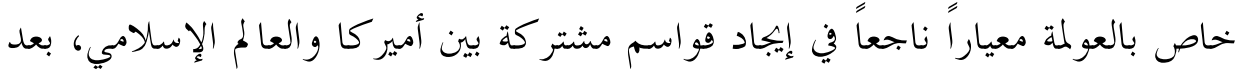
أن تعالت الصيحات داخل أمير كا نفسها متطلعة إلى نموذج معياري، يهقق مصــلحة

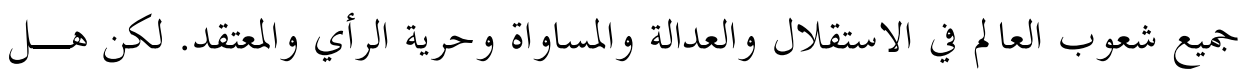

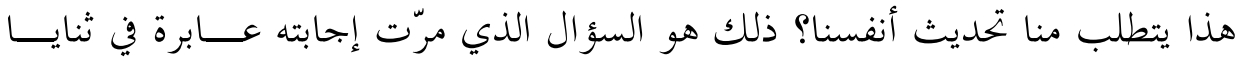

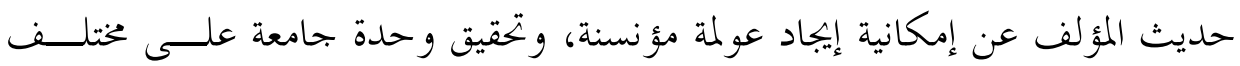
الصعد بين أبناء الأمة الإسلامية على تباين وعي فئاها و أفر ادها. من هنا تغدو القضية الإصلاحية عند المؤلف مرتكزة على: 


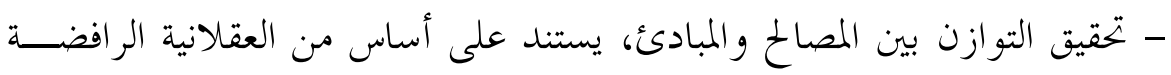

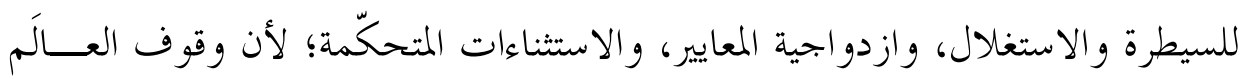

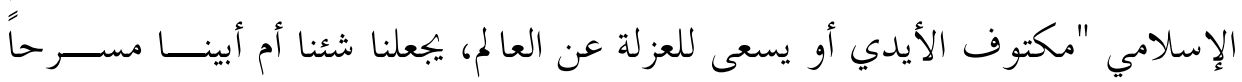

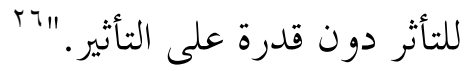

- التفاعل وعدم الانكفاء عن معطيات العصر، واسـتـخلاص العِسبر لتجربتــــا،

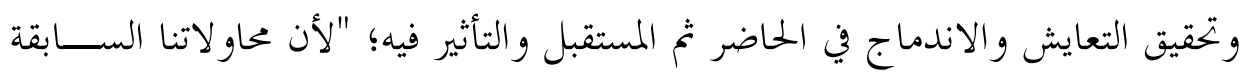

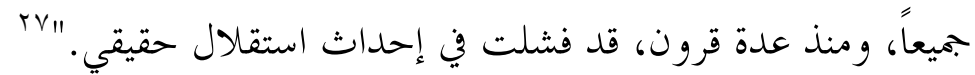

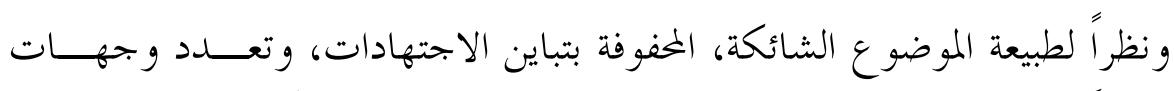

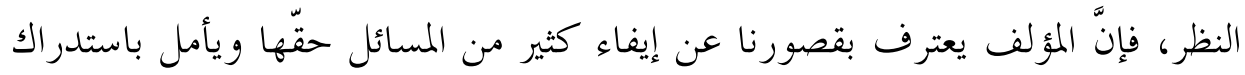

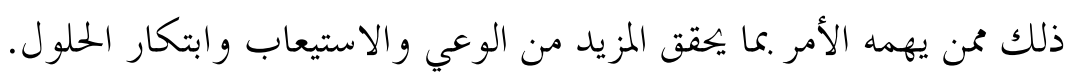

